\title{
Study of the fouling deposit in the heat exchangers of Algiers refinery
}

\author{
Rima Harche $\cdot$ Rafik Absi • Abdelkader Mouheb
}

Received: 15 February 2013/Accepted: 2 May 2014/Published online: 24 May 2014

(c) The Author(s) 2014. This article is published with open access at Springerlink.com

\begin{abstract}
The calculation of the calender-and-tube heat exchanger is based on empirical models validated on the laboratory scale. However, when doing an extrapolation at industrial scale, errors become significant because of the non-linearities of the thermophysical properties and the transfer coefficients along the heat exchanger. For that, a follow-up on the fouling resistance in heat exchangers of tube-calender type in Algiers' refinery is presented in this study. These exchangers are used to preheat the crude oil before its passage to the atmospheric column. The results obtained from the two cells of exchangers, which were studied, showed that the resistance and the deposit fouling increases with time following an exponential curve with the existence of the fluctuations caused by the instability of the flow. Bad cleaning of the exchangers involved the absence of an induction time, and consequently, caused high values of the resistance and the deposit fouling during a relatively short time.
\end{abstract}

Keywords Heat exchanger - Calender-and-tube · Modeling · Heat transfer coefficient - Fouling resistance Fouling deposit

R. Harche $(\bowtie) \cdot$ A. Mouheb

Laboratory of Transfer Phenomenon, Department of

Chemical Engineering, Faculty of Mechanical and Process

Engineering, University of Sciences and Technology Houari

Boumediene (USTHB), BP 32 EL-ALIA,

16111 Bab Ezzouar Algiers, Algeria

e-mail: rymou_2005@hotmail.com

R. Absi

EBI, Ecole de Biologie Industrielle, Inst. Polytech. Saint-Louis,

32 Boulevard du Port, 95094 Cergy-Pontoise Cedex, France

\section{List of symbols}

$R_{\mathrm{d}} \quad$ Fouling resistance $\left(\mathrm{m}^{2}{ }^{\circ} \mathrm{C} / \mathrm{kW}\right)$

$U_{\mathrm{S}} \quad$ Total coefficients of surface heat transfer at the dirty state $\left(\mathrm{kW} / \mathrm{m}^{2}{ }^{\circ} \mathrm{C}\right)$

$U_{\mathrm{P}} \quad$ Total coefficients of surface heat transfer at the clean state $\left(\mathrm{kW} / \mathrm{m}^{2}{ }^{\circ} \mathrm{C}\right)$

$m \quad$ The flow mass of the cold fluid (the crude oil) $\left(\mathrm{m}^{3} / \mathrm{h}\right)$

$C_{\mathrm{P}} \quad$ The heat-storage capacity $\left(\mathrm{kJ} / \mathrm{kg}{ }^{\circ} \mathrm{C}\right)$

$t_{\mathrm{e}}, t_{\mathrm{s}} \quad$ Output and input temperatures of the crude oil, respectively $\left({ }^{\circ} \mathrm{C}\right)$

$T_{\mathrm{e}}, T_{\mathrm{s}} \quad$ Output and input temperatures of the ebb of head, respectively $\left({ }^{\circ} \mathrm{C}\right)$

$P_{\mathrm{e}}, P_{\mathrm{s}} \quad$ Inlet and outlet pressure of the crude oil, respectively (bar)

A The external surface of heat transfer $\left(\mathrm{m}^{2}\right)$

$(F \Delta T \mathrm{~m}) \quad$ The difference in the logarithmic temperature $\left({ }^{\circ} \mathrm{C}\right)$

$e_{\mathrm{d}} \quad$ Deposit thickness (m)

$d_{4}^{15} \quad$ Density

$\lambda_{\mathrm{d}} \quad$ Deposit thermal conductivity $\left(\mathrm{kW} / \mathrm{m}{ }^{\circ} \mathrm{C}\right)$

$h_{0} \quad$ Heat transfer coefficient of external film $\left(\mathrm{kW} / \mathrm{m}^{2}{ }^{\circ} \mathrm{C}\right)$

$h_{\mathrm{i} 0} \quad$ Heat transfer coefficient of internal film brought back to external surface $\left(\mathrm{kW} / \mathrm{m}^{2}{ }^{\circ} \mathrm{C}\right)$

\section{Introduction}

The accumulation of deposits on a heat transfer surface leads to a reduction of the energy transfer effectiveness [1]. The resolution of this problem requires the prevention of deposition conditions or regular cleaning of the installations. These measurements involve significant financial penalties. In order to reduce these important operations and 
maintenance costs, the industrials need a better understanding of this phenomenon.

There is a large variety of deposit problems and installations types prone to fouling. In this study, we present a description of the deposit phenomenon for its modeling. Tools to understand fouling must be developed to provide quantitative information for the validation of the fouling models. Several studies were devoted to the parameters influencing the fouling deposit by chemical reactions. As an example, some studies showed that the rate of fouling increases with a reduction in the fluid temperature [2]. They explain this by the fact that at constant velocity and temperature, the increase in the thermal transfer involves an increase in fouling. Others observe, on the other hand, an increase in the rate of fouling with the fluid temperature [3, 4]. Radhakrishman et al. [5] developed a predictive model using statistical methods which can a priori predict the rate of fouling and decrease in heat transfer efficiency of heat exchangers. Aminian and Shahhosseini [6] evaluated the artificial neural network (ANN) modeling, for the prediction of crude oil fouling behavior in preheat exchangers of crude oil distillation units. This research showed that the influence of the crude oil velocity and tube diameter of the fouling rate is higher than the tube surface temperature. Mohanty and Singru [7] used the C-factor for monitoring of fouling in a calender-and-tube heat exchanger. Ishiyama et al. [8] consider in their work the problem of controlling the disaster inlet temperature by using hot stream bypassing, within a PHT fouling mitigation strategy based on heat exchanger cleaning. Wang et al. [9], in their results of heat transfer experiments show that the shell-side heat transfer coefficient of the improved heat exchanger increased by $18.2-25.5 \%$, the overall coefficient of heat transfer increased by $15.6-19.7 \%$, and the exergy efficiency increased by $12.9-14.1 \%$. Pressure losses increased by $44.6-48.8 \%$ with the solar installation. Sanaye and Hajabdollahi [10] used a first thermal model which is the eeNTU method which is applicable for optimal design of a shell and tube heat exchanger.

The fouling of heat exchanges used in refineries is an obstacle to their development.

In this study, we will consider the fouling phenomenon of the heat exchanger tubes for the preheat circuit of the Algiers refinery. The heat exchangers cells, E101 CBA and FED, which are used for the heating of the crude oil before its division are exposed to the problem of fouling at the tube side of heat exchangers. In this frame, a study of crude oil deposit on-site is realized which must allow to know its nature and the temporary evolution of the deposit thickness, and the most important point for this studies is to proved the linearization variation between the fouling resistance and the deposit thickness for each the two heat exchanger battery (E101 CBA and FED).
This study is composed by: a first part which presents the state of the art of fouling phenomenon, the second part presents the experimental study which was carried out in order to determine the evolution of the fouling resistance and the deposit thickness calculated based on a specific method of calculation presented in the third part, the fourth part includes our experimental results and discussions, and at the end we will finish by conclusions.

\section{Fouling phenomenon}

Fouling of heat transfer equipment is one of the most common operational problems confronted by the chemical processing industries. The main problem caused by fouling is related to the fact that the accumulation of fouling deposits has an important effect on the thermal and hydraulic performance of the affected equipment. The deposition of materials on heat transfer surfaces represents an additional resistance to the feat flow, which reduces the thermal effectiveness of the affected equipment [11].

Six different forms of fouling may occur in industrial applications, which include crystallization, particulate, chemical, corrosion, biological and solidification fouling [12].

This part considers again the various sources at the origin of this phenomenon. It is also shown how this fouling reduces the exchanger effectiveness. We will be interested in following thermal consequence of the deposit.

\section{Origins of the fouling phenomenon}

The term of fouling refers in general to any type of fouling deposit matter on the heat transfer surface. The nature of the deposit strongly depends on the composition of the fluid treated by the exchanger. The fluid can be itself at the origin of the deposit, by organic decomposition under conditions of favorable temperature and pressure. But fouling can also come from solid or semi-solid materials in suspension in the fluid.

However, all these mechanisms can be described in three stages:

1. The diffusive transport of material and its precursors through the boundary layer in close wall.

2. The adherence and the wrenching of material on the surface (clean or fouling).

3. The convective transport of this one far from the surface.

In an idealized way, Fig. 1 shows these three major stages of a fouling mechanism.

The first part (A) corresponds to the initiation phase. This period depends largely on the deposit type varies few minutes at a few weeks, for example in the air-conditioning 
systems [13]. The second part (B) corresponds to the increase in this deposit resulting from a competition between the mechanisms from deposit and wrenching. The fouling rate decreases gradually while wrenching increases, finally, leading that to a balance in (C) and a height fouling held constant.

The thermal sense of deposit

The accumulation of deposits in heat exchanger surfaces increases resistance to the heat flow. The profile of temperature under "clean" condition without deposit (index p) is shown in Fig. 2a, and under "fouling" condition (index E) in Fig. 2b. In the case of refinery, the crude oil temperature exit $\left(T_{5}\right)$ is higher than temperatures $T_{1}$ (shown in figure 2) and $T_{5}$, which represent the hot gas temperatures. In the close zones wall, the fluid is slowed down and thus the heat transfer is reduced. In addition, the deposit thermal conductivity is low compared to that of metals. For these

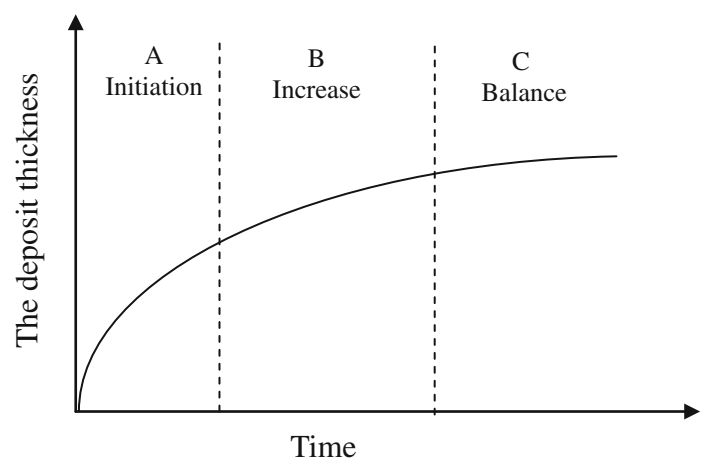

Fig. 1 Three phases of a deposit mechanism: the deposit thickness according to time [4]

reasons, the heat transfer through the deposit requires significant differences.

In order to understand the fouling phenomenon, an experimental study was conducted on-site, and it is presented in the next section.

\section{Experimental procedure}

The study was made on the level of three heat exchanger cells of the circuit preheats of the Algiers refinery. The crude oil leaves the vat of storage at room temperature; one of the three centrifugal pumps P101, drives back it towards the atmospheric unit of distillation U101, while crossing the two circuits of the E101 battery E101 CBA and E101 FED, which is the tube-calenders type with a floating head. The crude crosses the battery with dimensions tube where it is heated using the backward flow head, that is a mixture of light products, coming from the top of the fractionating column C101 on the level of the plate N46. Oil passes them by the electrostatic disaster by the addition of treated water and caustic soda. Treated water is injected at the entry of the E101 exchanger and the entry of the disaster, with an aim of the crude oil washing and of involved with it salts present there (Fig. 3). Each cell is made up of three heat exchangers, laid out in a series (Fig. 4).

The characteristics of these exchangers are presented in the Table below (Table 1):

Our experimental study is based on the following assumptions.

1. The same crude oil flow crosses the tube side for each exchanger,

2. The same backward flow crosses the calenders side for each exchanger,

Fig. 2 Temperature profile through the wall of a clean tube (a) and a fouling tube (b) in an exchanger [14]

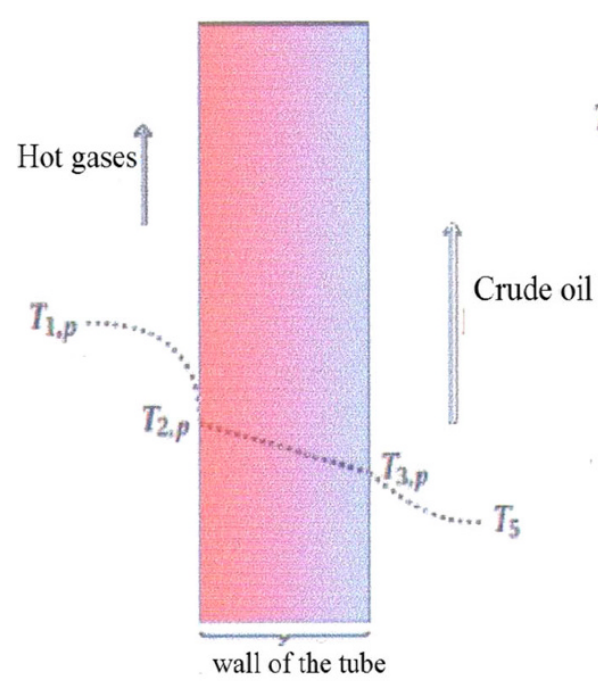

(a) Clean tube

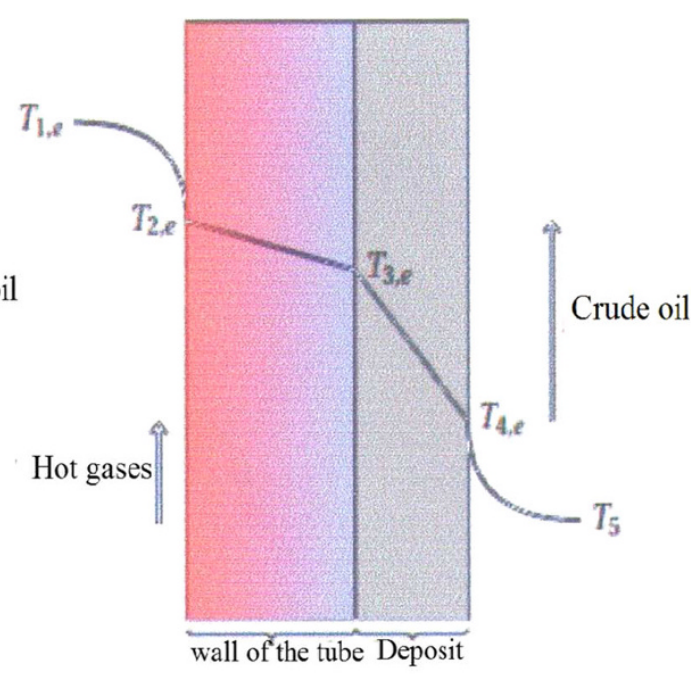

(b) Fouling tube 
Fig. 3 Simplified diagram of the crude oil preheats circuit

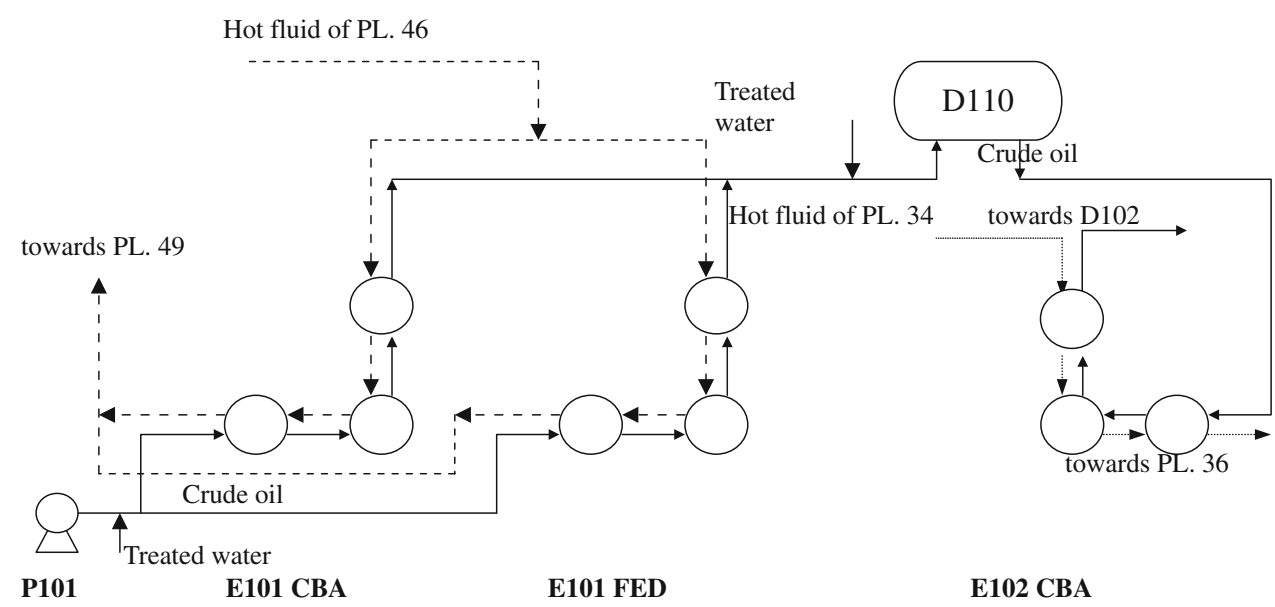

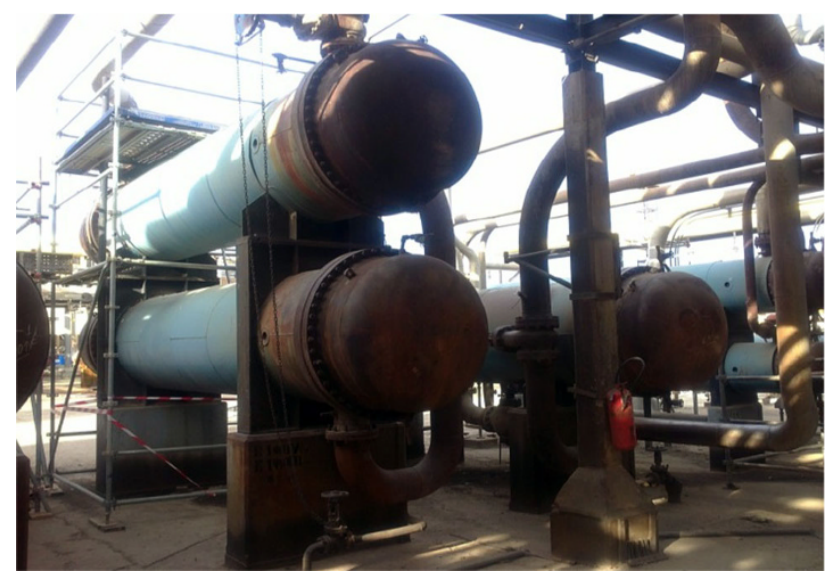

Fig. 4 Picture of the E101 CBA heat exchanger

3. The number of total tubes is the sum of the each heat exchanger tube,

4. The total number of tube side master keys is equal to three times of the number of tube side master keys for each heat exchanger,

5. The output and input temperatures of the two fluids are taken at the ends of the cell.

We measured both cold and hot temperatures, respectively, on tube side (crude oil) and calender side (ebb of head) each $2 \mathrm{~h}$ from 8 to $14 \mathrm{~h}$. At each time we note also the flow rate of the two fluids. At the end of the day, we obtain therefore an average temperature and flow rate values.

The calculation method, for the fouling resistance and the deposit thickness based on our results and the available data, is presented in the next section.

\section{Calculation method}

In the present study, the temporal evolution of the crude oil fouling resistance was studied by considering each cell
Table 1 Characteristics of the heat exchangers cells

\begin{tabular}{lll}
\hline Characteristics & E101 CBA FED \\
\cline { 2 - 3 } & $\begin{array}{l}\text { Calenders } \\
\text { side }\end{array}$ & $\begin{array}{l}\text { Tubes } \\
\text { side }\end{array}$ \\
\hline Fluid circulating & $\begin{array}{l}\text { Ebb of head } \\
\text { Flow mass (lb/h) }\end{array}$ & $\begin{array}{l}\text { Crude oil } \\
\text { Density API }\end{array}$ \\
Viscosity (cS) & $76.000,000.00$ & 715.260 \\
Input/output & - & 44.40 \\
Input temperature (F) & & $2.40-0.96$ \\
Output temperature (F) & 240 & \\
A number of master keys & 150 & 80 \\
Fouling factor of & 1 & 220 \\
$\Delta P_{\text {acceptable }}$ (bars) & 0.001 & 4 \\
Material of construction & - & 0.002 \\
Calender diameter (in.) & Carbon steel & \\
Distance between chicanes (in.) & 42 & \\
Number of calenders & 18 & \\
External diameter of tubes (in.) & 6 & \\
Thickness of tubes & 0.75 & \\
Length of tubes (in.) & BWG 14 & \\
Total number of tubes & 20 & \\
The step: opposite square (in.) & $6,600.00$ & \\
Total surface of heat exchange ( $\mathrm{ft}^{2}$ ) & $25,000.00$ & \\
Global coefficient of heat exchange & 63.5 & \\
in the clean state (Btu/h $\mathrm{ft}^{2}{ }^{\circ} \mathrm{F}$ ) & & \\
\hline
\end{tabular}

consisting of three exchangers in series. Taking into account that it is not possible to measure all temperatures, we considered the three exchangers as a single one. As noticed, only one exchanger with three master keys and 12 master keys with a tube for each cell E101 CBA and FED.

The calculation of the fouling resistance was made by using the following relation:

$R_{\mathrm{d}}=\left(\frac{1}{U_{\mathrm{s}}}\right)-\left(\frac{1}{U_{\mathrm{p}}}\right)$. 
$U_{\mathrm{S}}$ and $U_{\mathrm{P}}$ are the total of heat transfer surface coefficients of the dirty state and the clean state, respectively.

The total of heat transfer surface coefficients of the dirty state was given in the time course, via the expression:

$U_{\mathrm{s}}=\frac{m \cdot c_{\mathrm{p}} \cdot\left(t_{\mathrm{s}}-t_{\mathrm{e}}\right)}{A \cdot F \cdot \Delta T_{\mathrm{m}}}$

where $m$ is the flow mass of the cold fluid (the crude oil), $C_{\mathrm{P}}$ is the heat-storage capacity, $t_{\mathrm{e}}$ and $t_{\mathrm{s}}$ are the output and input temperatures, respectively, $A$ the external surface of heat transfer $\left(F \Delta T_{\mathrm{m}}\right)$ the difference in the logarithmic temperature; and $U_{\mathrm{S}}$ is the total of heat transfer coefficients brought back to external surface.

This relation is drawn from the assessment of energy on the heat exchanger by supposing the isolated system and the physical properties of the two fluids, as well as, the heat transfer coefficients remain constant along the exchanger.

\section{Calculation of $U_{\mathrm{p}}$}

In the Algiers refinery, the operating conditions at the boundaries of the E101 exchanger are variable, it is necessary to revalue the total of heat exchange coefficients in the proper conditions $U_{\mathrm{p}}$ corresponding to the new operating conditions:

$U_{p}=h_{0} h_{i 0} /\left(h_{0}+h_{i 0}\right)$.

With:

$h_{0}$ : The heat transfer coefficient of external film.

$h_{\mathrm{i} 0}$ : The heat transfer coefficient of internal film brought back to the external surface.

Study of the deposit thickness

The deposit thickness needs the fouling resistance and is obtained by the following correlation:

$R_{\mathrm{d}}=\frac{e_{\mathrm{d}}}{\lambda_{\mathrm{d}}} \quad \Rightarrow \quad e_{\mathrm{d}}=R_{\mathrm{d}} \cdot \lambda_{\mathrm{d}}$

However,

$R_{\mathrm{d}}$, represents the fouling resistance;

$e_{\mathrm{d}}$, the deposit thickness;

$\lambda_{\mathrm{d}}$, the deposit thermal conductivity calculated by the Sahoo correlation (2001) [15].

For this entire calculation one uses the following fluid characteristics (Table 2):

According to our results and the data of the operating parameters obtained from the Algiers refinery (see Table 3); graphs and the deposit analyses are grouped under the title of experimental results.
Table 2 Fluid characteristics

\begin{tabular}{lll}
\hline Characteristics & $\begin{array}{l}\text { Cold fluid } \\
\text { Crude oil }\end{array}$ & $\begin{array}{l}\text { Hot fluid } \\
\text { Ebb of head }\end{array}$ \\
\hline $\begin{array}{l}\text { Density } \\
\text { Kinematic viscosity }\end{array}$ & 0.7966 & 0.7231 \\
$20.0{ }^{\circ} \mathrm{C} / 68{ }^{\circ} \mathrm{F}$ & 2.83 & 0.63 at $30{ }^{\circ} \mathrm{C}$ \\
$37.8{ }^{\circ} \mathrm{C} / 100{ }^{\circ} \mathrm{F}$ & 2.02 & 0.57 at $40{ }^{\circ} \mathrm{C}$ \\
Sulphur content $(\%$ mass $)$ & 0.0634 & - \\
Characterization factor, Kuop & 12.20 & - \\
Molecular weight (g/mol) & 189 & - \\
Asphaltene content $(\%$ mass $)$ & 0.07 & - \\
\hline
\end{tabular}

\section{Results and discussion}

Temporal evolution of the fouling resistance

Figure 5 shows that the temporary evolution of the fouling resistance approaches the exponential form, in spite of the deviation of some experimental points.

It is also noticed, that Fig. 5 which presents the temporary evolution of the fouling resistance for the heat exchanger battery E $101 \mathrm{CBA}$ and E101 FED of Algiers refinery, seems to follow an asymptotic evolution which is in agreement with the model of Kern and Seaton [16], with the absence of the induction period. That can be explained by the delay recorded between last cleaning, and the beginning of experiments. As it appears clearly that the fouling resistance increases with time until reaching an asymptotic value which is about the $3 \mathrm{~m}^{2}{ }^{\circ} \mathrm{C} / \mathrm{kW}$ for the series of exchanger E101 CBA, and about $2 \mathrm{~m}^{2}{ }^{\circ} \mathrm{C} / \mathrm{kW}$ for the series of exchanger E101 FED; this is in the first part of the curve which varies at the time from 660 to 700 days, beyond the fouling resistance decreases because of the need for an emergency stop for the one exchanger of the battery E101 CBA. In the same way, it is noted that fouling resistance is higher in battery E101 CBA than in battery E101 FED; and this is right because of the position of the one compared to the other (the first battery undergoes a higher flow of crude oil and the more fouling).

The deposit analysis

During the cleaning of the cells heat exchangers E101 CBA at the end of the study, samples of both cell deposits were taken for analysis, having used two methods.

\section{Chemical analysis of the deposit}

Table 4 groups the various chemical analyses made for both cell deposits. 
Table 3 Some values of the available data

\begin{tabular}{|c|c|c|c|c|c|c|c|c|c|}
\hline \multirow[t]{2}{*}{ Days } & \multicolumn{6}{|c|}{ The crude oil } & \multicolumn{3}{|c|}{ Ebb of head } \\
\hline & $t_{\mathrm{e}}\left({ }^{\circ} \mathrm{C}\right)$ & $t_{\mathrm{s}}\left({ }^{\circ} \mathrm{C}\right)$ & $Q\left(\mathrm{~m}^{3} / \mathrm{h}\right)$ & $d_{4}^{15}$ & $P_{\mathrm{e}}($ bars $)$ & $P_{\mathrm{s}}($ bars $)$ & $T_{\mathrm{e}}\left({ }^{\circ} \mathrm{C}\right)$ & $T_{\mathrm{s}}\left({ }^{\circ} \mathrm{C}\right)$ & $Q\left(\mathrm{~m}^{3} / \mathrm{h}\right)$ \\
\hline \multicolumn{10}{|c|}{ E101 CBA heat exchanger } \\
\hline 01.04 .2010 & 19.00 & 100.00 & 217.698 & 0.790 & 16.85 & 14.93 & 122.50 & 58.00 & 341.822 \\
\hline 02.04 .2010 & 19.00 & 100.25 & 204.892 & 0.789 & 16.90 & 15.05 & 122.00 & 57.00 & 326.951 \\
\hline 05.04 .2010 & 17.75 & 99.50 & 221.060 & 0.786 & 17.03 & 14.83 & 122.75 & 57.50 & 347.924 \\
\hline 06.04 .2010 & 18.00 & 101.50 & 222.415 & 0.791 & 17.00 & 15.08 & 124.50 & 58.25 & 347.269 \\
\hline 07.04 .2010 & 18.63 & 102.50 & 212.980 & 0.787 & 17.65 & 15.45 & 123.50 & 58.50 & 346.030 \\
\hline 09.04.2010 & 19.00 & 102.50 & 217.672 & 0.788 & 17.05 & 15.10 & 123.00 & 59.13 & 349.090 \\
\hline 12.04 .2010 & 19.13 & 103.25 & 215.002 & 0.790 & 16.98 & 14.98 & 123.75 & 60.25 & 351.713 \\
\hline \multicolumn{10}{|c|}{ E101 FED heat exchanger } \\
\hline 01.04 .2010 & 19.25 & 100.00 & 217.698 & 0.790 & 16.73 & 14.18 & 122.50 & 58.00 & 341.822 \\
\hline 02.04 .2010 & 19.00 & 100.00 & 204.892 & 0.789 & 16.93 & 15.50 & 122.00 & 57.00 & 326.951 \\
\hline 05.04 .2010 & 17.75 & 99.50 & 221.067 & 0.786 & 17.00 & 14.50 & 122.75 & 57.50 & 347.924 \\
\hline 06.04 .2010 & 18.00 & 100.00 & 222.415 & 0.791 & 16.85 & 14.28 & 124.50 & 58.25 & 347.269 \\
\hline 07.04 .2010 & 18,75 & 100.75 & 212.980 & 0.787 & 17.48 & 15.03 & 123.50 & 58.50 & 346.030 \\
\hline 09.04 .2010 & 19.00 & 100.00 & 217.672 & 0.788 & 17.68 & 14.40 & 123.00 & 59.13 & 349.090 \\
\hline 12.04 .2010 & 19.13 & 101.00 & 215.002 & 0.790 & 16.80 & 14.28 & 123.75 & 52.55 & 351.713 \\
\hline
\end{tabular}

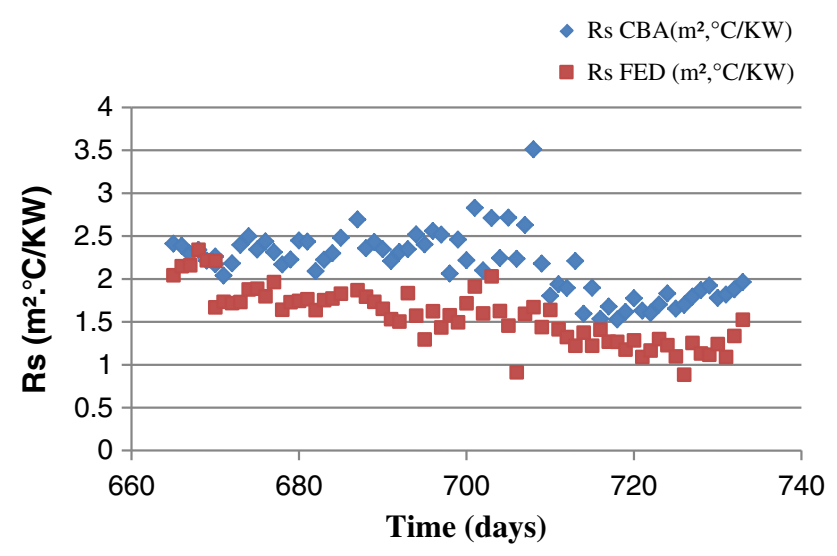

Fig. 5 Temporal evolution of the fouling resistance for the two series of exchangers

Table 4 Chemical analysis of the heat exchangers deposits

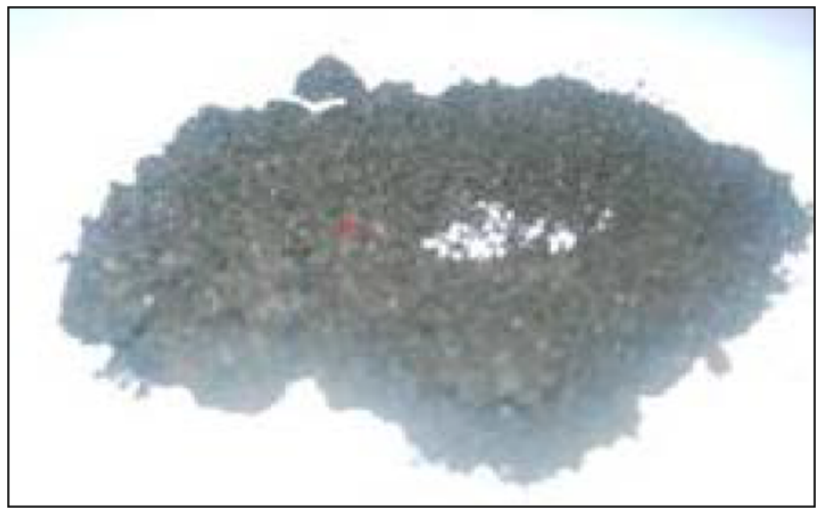

Fig. 6 Samples of the crude oil deposit

These analyses let suppose that the composition of the deposit is a little unexpected. According to the Table 4, the observations which can be made are the following below:

- A content with raised insolubles.

- A low content in the hydrocarbons and in the silica.

- Of strong contents in the sulfates and in the chlorides.

- The iron is a considerable content.

\section{Electron microscope analysis}

To be able to know the deposit composition, samples of the deposit (calenders and tubes side for the two batteries of exchanger) (see Fig. 6) were analyzed under the scanning 


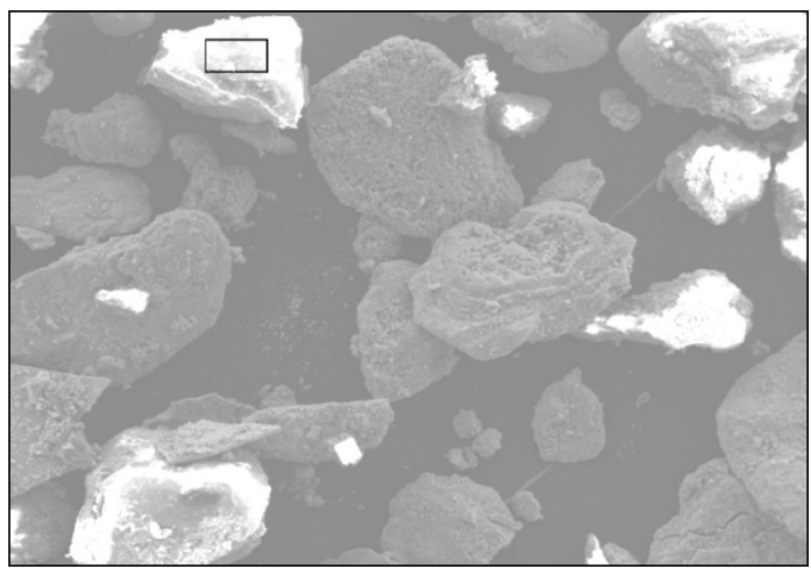

Fig. 7 Picture of the sample structure of crude oil deposit analyzed by microscope

Table 5 Composition of a sample of the crude oil deposit

Wt $\%$ the mass percentage, At\% the atomic percentage

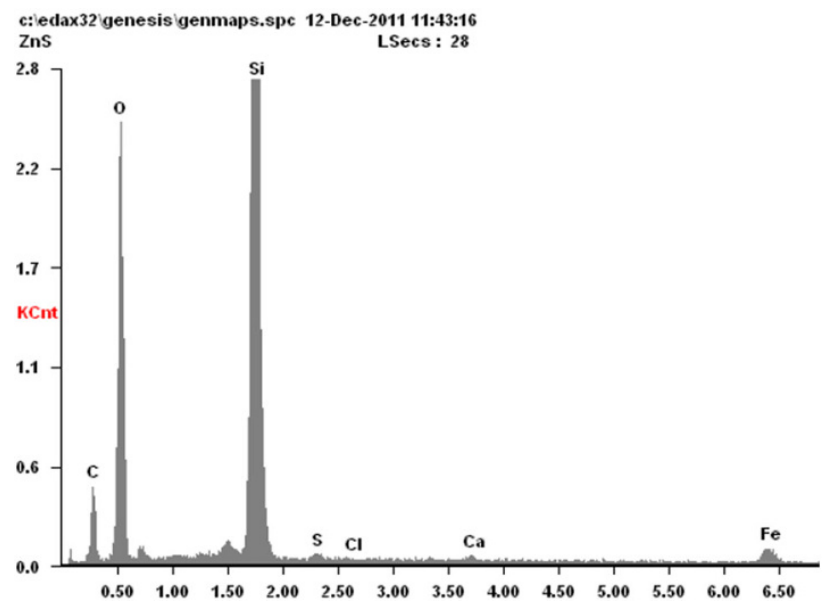

Fig. 8 Energy spectrum of the crude oil deposit by the EDS technique

by electron microscope, which gives an exact image of the deposit structure represented in Fig. 7.

According to analyses of the crude oil deposit, the composition is given by Table 5 .

The results of the Table 5 are represented in Fig. 8 which define each element by a quite precise peak.

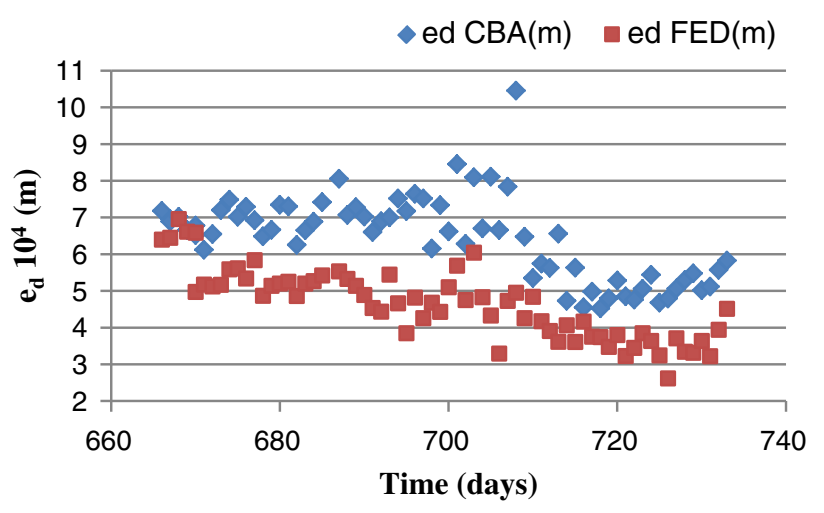

Fig. 9 Temporary evolution of deposit thickness for two series of exchangers

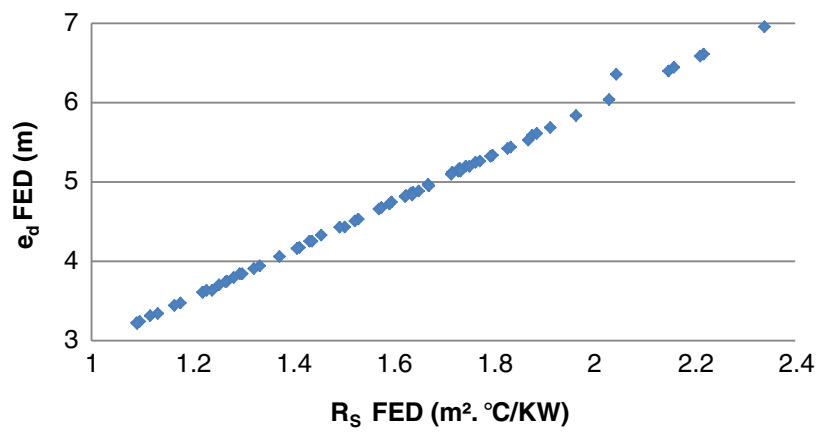

Fig. 10 Variation of deposit thickness with fouling resistance for E101 FED series

The deposition kinetics

All the experimental results obtained during the various taking away present the same pace as that of Fig. 9, which give the temporal evolution of the deposit thickness for two series of exchangers E101 CBA and E101 FED.

A made observation is that the shape of the curve has an exponential evolution which agrees with the model of Kern and Seaton [16] which was already checked in the first part of the study.

Figure 9 represents two areas: firstly, the deposit thickness increases gradually until reaching a known limiting value under the name of the asymptotic value, and this in a transitory flow mode.

Additionally, in the second part of this graph, deposit thickness decreases and this because of an emergency stopping of the E101 CBA heat exchanger battery.

In the same way, it is noticed that the deposit thickness is higher in the battery E101 CBA than in the battery E101 FED; one notes that the deposit thickness varies proportionally with the fouling resistance and that is quite precise in Fig. 10, which represents the variation of the deposit thickness according to the fouling resistance for the E101 FED exchanger battery. 


\section{Conclusion}

The present study allows a better understanding, from a viewpoint of a thermo energy, of the fouling effect in the tubular heat exchangers of the preheat circuit of Algiers refinery. The study concerned the battery E101CBA and FED allowed deposit analysis, the determination of both time-dependent fouling resistance and deposit thickness and the variation of deposit thickness according to fouling resistance. The results obtained revealed an exponential evolution of the fouling resistance, in conformity with the model of Kern and Seaton with the absence of the induction period, which is explained by the consequence of a bad cleaning, or a gap between the present study and the beginning of the functioning of the heat exchangers after the last stop. We had a more important increase of the fouling resistance in the first battery E101 CBA than in the second battery E101 FED. This is obviously because the crude oil flow is higher in the first battery compared to the second battery.

During the cleaning of the heat exchangers, samples of the deposit were taken for analyses. Two methods were used:

During the cleaning of the heat exchangers, samples of the deposit were taken for analyses. Two methods were used. The first method used the chemical analysis. The results showed the coexistence of three to four types of fouling: precipitation fouling (presence of salts), particulate fouling (presence of insoluble), chemical reaction fouling (presence of hydrocarbons), and corrosion fouling (presence of iron, for example). The second method of analysis by electron microscope scanning, allows to find the same types of fouling and this confirms the former results. Finally, we proved the linear relation between the deposit thickness and the fouling resistance for each series of the exchanger battery.

Open Access This article is distributed under the terms of the Creative Commons Attribution License which permits any use, distribution, and reproduction in any medium, provided the original author(s) and the source are credited.

\section{References}

1. Pedot Th (2012) Modélisation du couplage thermique entre la combustion et l'encrassement des tubes d'un four de raffinerie. $\mathrm{Ph} . \mathrm{D}$. Thesis. University of Toulouse

2. Srinivasan M (2005) Heat exchanger fouling of some Canadian crude oils. Heat Transf Eng 26:7-14

3. Asomaning S (1997) Heat exchanger fouling by petroleum asphaltenes. Ph.D. Thesis. University of British Columbia

4. Saleh Z, Sheikholeslami R, Pwatkinson A (2005) Fouling characteristics of a light Australian crude oil. Heat Transf Eng 26:15-22

5. Radhakrishman VR, Ramasamy M (2005) Heat exchanger fouling model and preventive maintenance scheduling tool. Appl Therm Eng 27:2791-2802

6. Aminiam J, Shahhosseini S (2008) Evaluation of ANN modeling for prediction of crude oil fouling behavior. Appl Therm Eng 28: 668-674

7. Mohanty DK, Singru PM (2001) Use of C-factor for monitoring of fouling in a shell and tube heat exchanger. Appl Therm Eng 36:2899-2904

8. Ishiyama EM, Heins AV, Paterson WR, Spinelli L, Wilson DL (2010) Scheduling cleaning in a crude oil preheats train subject to fouling: incorporating desalter control. Appl Therm Eng 30:1852-1862

9. Wang S, Wen J, Yanzhong L (2009) An experimental investigation of heat transfer enhancement for a shell-and-tube heat exchanger. Appl Therm Eng 29:2433-2438

10. Sanaye S, Hajabdollahi H (2010) Multi-objective optimization of shell and tube heat exchangers. Appl Therm Eng 30:1937-1945

11. Rodriguez C, Smith R (2007) Optimization of operating conditions for mitigating fouling in heat exchanger networks. Chem Eng Res Des 85:839-851

12. Lei Ch, Peng Z, Day Th, Yan X, Bai X (2011) Experimental observation of surface morphology effect on crystallization fouling in plate heat exchangers. Int Commun Heat Mass Transfer 38:25-30

13. Zhi-Ming XU, Zhong-Bin Z, Yang S (2007) Costs due to utility fouling in china. ECI Symposium series, Proceedings of 7th International Conference on Heat Exchanger Fouling and Cleaning challenges and opportunities 16, p 113-118

14. Bott T (1995) The book of: Fouling of heat exchangers: chemical engineering monographs. Elsevier, p 524 ISBN: 0080531903/ 9780080531908

15. Manglik RM, Bergles AE (1993) Heat transfer and pressure drop correlations for twisted tap inserts in isothermal tubes: part Ilaminar flows. J Heat Trans T ASME 115:881-889

16. Butterworth D (2002) Design of shell and tube heat exchangers when the fouling depends on local temperature and velocity. Appl Therm Eng 22:789-801 